\title{
How Primary Care Networks Can Help Integrate Academic and Service Initiatives in Primary Care
}

\author{
Paul Thomas, MD, FRCGP ${ }^{1}$ \\ Jonathan Graffy, MD, FRCGP \\ Paul Wallace, MSc, FRCGP ${ }^{3}$ \\ Mike Kirby, MRCP, MRCP ${ }^{4}$ \\ ${ }^{1}$ Centre for Study of Policy and Practice in \\ Health and Social Care, Thames Valley \\ University, Westel House, London, England \\ ${ }^{2}$ General Practice and Primary Care Research \\ Unit, Institute of Public Health, University \\ of Cambridge, Cambridge, England \\ ${ }^{3}$ Department of Primary Care and Population \\ Sciences, Royal Free and University College \\ School of Medicine, London, England \\ ${ }^{4}$ The Nevells Road Surgery, Letchworth \\ Garden City, Herts, and Faculty of Health \\ \& Human Sciences, University of Hertford- \\ shire, Hatfield, Herts, England
}

Conflicts of interest: Paul Thomas designed and led Network D as network director; Jonathan Graffy designed and led Network $C$ as network director; Paul Wallace designed and led Network B as network director; Mike Kirby codesigned and led Network A as network director.

\section{CORRESPONDING AUTHOR}

Paul Thomas, MD, FRCGP

Centre for Study of Policy and Practice

in Health and Social Care

Thames Valley University

Westel House

32-38 Uxbridge Rd

Ealing, London W5 2BS, England

Paul.Thomas@tvu.ac.uk

\begin{abstract}
PURPOSE Theory of effective network operation in primary care is underdeveloped. This study aimed to identify how primary care networks can best integrate academic and service initiatives.
\end{abstract}

METHODS We performed a comparative case study of 4 primary care research networks in North London, England, for the years 1998-2002. Indicators were selected to assess changes in (1) research capacity, (2) multidisciplinary collaboration, and (3) research productivity. We compared the profiles of network outcome with descriptions of their contexts and organizational types from a previous evaluation.

RESULTS Together, the networks supported 133 viable projects and 30 others; 399 practitioners, managers, and academics participated in the research teams. How the networks organized themselves was influenced by the circumstances in which they were formed. Different ways of organizing were associated with different outcome profiles. Shared projects and learning spaces helped participants to develop trusted relationships. A top-down, hierarchical approach based on institutional alliances and academic expertise attracted more funding and appeared to be stable. The bottom-up, individualistic network with research practices was good at reflecting on practical primary care concerns. Whole-system methods brought together stakeholder contributions from all parts of the system.

CONCLUSIONS Networks can help integrate academic research and service development initiatives by facilitating interorganizational interactions and in shared leadership of projects. Researchers and practitioners stand to gain considerably from an integrated approach in both the short and the long term. Success requires agreement about a set of pathways, learning spaces, and feedback mechanisms to harness the insights and efforts of stakeholders throughout the whole system.

Ann Fam Med 2006;4:235-239. DOI: 10.1370/afm.521.

\section{INTRODUCTION}

$\mathrm{n}$ a review of primary care research networks (PCRNs), we described their potential to integrate different efforts for quality, including education and

service. ${ }^{1}$ In the United States, the need for integratation of health care services is a key recommendation of the Future of Family Medicine project. ${ }^{2}$ In the United Kingdom, it is a promise of the present government. ${ }^{3}$

Since 1998, it has been UK government strategy to fund PCRNs. Now these networks are to amalgamate to cover larger areas. They are intended to work closely with topic-specific research networks conducting studies on cancer, diabetes, mental health, stroke, dementia, and medicine for children. ${ }^{4}$ At the same time, commissioning for services will be devolved to localities of primary care organizations $\left(\mathrm{PCOs}^{*}\right){ }_{1}^{5}$ promoting locality-based research into health needs and service provision.

* PCOs are organizations that coordinate services for populations of about 250,000. 
We write as the initial directors of 4 PCRNs that started in 1998 in North London, England, to serve adjacent geographic areas. We inherited very different contexts and consequently chose different strategies. Table 1 describes several different approaches to understanding the structure and organization of networks that we have found helpful.

Three of our networks exemplified the ideal types $^{6}$ of PCRN leadership that we have previously described. ${ }^{1}$ Top-down leadership indicates that institutions set policy and that experts lead projects. Bottom-up leadership indicates that peripherally placed practitioners and academics develop their ideas locally. Whole-system leadership indicates that the different teams engaging with the network are able to contribute to policy through an annual cycle of strategy review.

In 2003, the UK Service Development and Organisation (SDO) Programme, which funds research into health service organizations, commissioned a systematic review of the literature about public and private sector networks to draw lessons about network management. $^{7}$ The study identified 3 types of network structure: enclave, a structure based on shared commitment ${ }_{i}$ bierarchical, one with a regulatory organizational core, and individualistic, one with a loose association of affiliates. We believe that these descriptions fit 3 of our networks well.

An external team of researchers from Warwick University evaluated our networks. Through interviews, observation, and review of documents, they described the context and strategy that each network had adopted, analyzed initial strengths and weaknesses, and categorized each network according to its prime aim. ${ }^{8}$

\section{METHODS}

\section{Comparative Analyses}

We adopted a comparative case study approach, first describing the context that gave rise to decisions about organizational strategy in each network. This information was in part drawn from the analysis made by the research team from the University of Warwick. ${ }^{8}$

We then compared the success of the networks in achieving the different objectives defined by the UK Department of Health, namely, research capacity, multidisciplinary collaboration, and research productivity. Proxy indicators of these outcomes were used to assess progress. To indicate increasing research capacity in primary care, we compared the number of researchers with and without an academic post and the breadth of disciplines in the research teams; to indicate interorganizational collaboration, the proportion of projects that involved partnerships between general practices and other organizations; to indicate research productivity, the number of viable projects, external grant income, and research dissemination.

We obtained a list of the projects that each network was supporting in April 2001. We validated this list by comparing it with network literature (annual reports, bulletins, and conference presentations) to avoid omissions or duplication. One author (PT) then conducted structured telephone interviews to gather data on activity until December 2001. In 3 of the networks, these interviews were with principal investigators; in Network $B$, interviews were conducted with network staff who provided information from office records.

\section{Network Concepts: Nodes, Ties, and Centralization}

A network comprises "a set of nodes and the set of ties representing some relationship, or lack of relationship, between the nodes." ${ }^{\prime \prime}$ Nodes are are people, places, or organizations that enable multidisciplinary transfer of information, broker partnerships for quality improvements, and access a variety of resources and power. They are places where different paths converge, and the means whereby a network reaches places that bureaucratic structures cannot reach. ${ }^{10}$

Social network theory shows how to measure the

Table 1. Typologies of Networks

\begin{tabular}{|c|c|c|c|}
\hline Network & $\begin{array}{l}\text { Our Taxonomy of Network } \\
\text { Leadership }\end{array}$ & SDO Taxonomy of Network Structure & $\begin{array}{l}\text { Warwick Analysis of Main } \\
\text { Network Aims }\end{array}$ \\
\hline A & (Not recognized in taxonomy) & $\begin{array}{l}\text { Enclave: has a flat internal structure with no cen- } \\
\text { tral authority; based on shared commitment }\end{array}$ & $\begin{array}{l}\text { Mobilization: aims to mobilize local } \\
\text { practitioners for research }\end{array}$ \\
\hline B & $\begin{array}{l}\text { Top down: led by a university-health } \\
\text { care organization alliance }\end{array}$ & $\begin{array}{l}\text { Hierarchical: has an organizational core and } \\
\text { authority to regulate the work of members }\end{array}$ & $\begin{array}{l}\text { Facilitative: aims to facilitate local par- } \\
\text { ticipation in academic-led research }\end{array}$ \\
\hline C & $\begin{array}{l}\text { Bottom up: led by } 7 \text { research general } \\
\text { practices }\end{array}$ & $\begin{array}{l}\text { Individualistic: has a loose association of } \\
\text { affiliates developed by an individual or } \\
\text { organization }\end{array}$ & $\begin{array}{l}\text { Consolidation: aims to consolidate } \\
\text { the competencies of practices }\end{array}$ \\
\hline D & $\begin{array}{l}\text { Whole system: led by different groups } \\
\text { that influenced policy through a } \\
\text { cycle of ongoing strategic review }\end{array}$ & (Not recognized in taxonomy) & $\begin{array}{l}\text { Transformational: aims to change } \\
\text { relationships throughout the whole } \\
\text { system }\end{array}$ \\
\hline
\end{tabular}


frequency and intensity of exchange of information and influence between nodes, building a rich understanding of the complex relationships (ties) that a network can develop. ${ }^{10}$ It also offers concepts to examine networks as whole entities. Centralization is the degree to which different members are central or peripheral to power; a highly centralized network is hierarchical, with few actors very central and the rest connected only to these central actors. Density is the number of ties in the network in proportion to the number of possible ties. ${ }^{10}$

In this article, we present the results of an analysis of our networks using the concepts of node, tie, and centralization. We intend to show the networks in a way a bird might observe the flow of travelers throughout a railway network. Nodes are the railway stations and junctions where many different people interact; in our networks, they are conferences and workshops where different network members learn from and with each other. Ties refer to relationships between network members and manifest as cross-organizational partnerships, committee meetings, and multidisciplinary research teams. Centralization refers to the mechanisms of policy formation, including executive management groups, formal and informal leaders, think-tanks, and ways that intelligence throughout the network influences overall direction.

\section{RESULTS}

The online-only Supplemental Appendix describes the context and provides comparative data about the net-

works, and is available at http://www.annfammed. org/cgi/current/full/4/3/235/DC1.

During their first 3 years, the networks supported 133 projects, only 9 of which had started before the networks began. The networks had withdrawn support for a further 30 projects because of delayed progress. The 133 viable research teams included 399 individuals, of whom 277 (69\%) did not have an academic post. These included 118 general practitioners $(30 \%), 148$ other primary care practitioners and managers $(37 \%)$, and 133 others, mainly hospital clinicians and nonclinical academics (33\%).

Each network had a facilitation team and a management group that developed systems for research governance, allocation of funds, training, and advice. Each held an annual conference that provided an important node for stakeholders to interact, learn, and initiate collaborative work. After 2001, each network reviewed its strategy and, with time, each has adopted features of the others. Despite these similarities, each offered a distinct insight into effective network function.

\section{Network A}

Network A, which has an enclave structure, served a suburban rural population of 1.1 million. Unlike the situation in the other 3 networks, there was little initial need in this network to integrate different interests for research, because the network had few organizational ties and little previous primary care research. It was the only network with no affiliated medical school. A steering group, open to all members, met monthly to consider network strategy and to develop projects. Policy was centralized within this group, which also had strong ties between members. Nodes developed in response to specific projects.

The breadth of activity from this network was less than that from the others. It supported 42 individual researchers, of whom 6 had an academic post, to undertake 9 projects. By December 2001, it had 8 peerreviewed publications.

This network's approach shows the power of learning spaces (nodes) and shared projects to help develop trusted relationships. This pattern supports the SDO conclusion that enclave networks "are most successful in enabling information and ideas to be shared among professionals with a common interest."7

\section{Network B}

Network B, which has a hierarchical/top-down structure, developed policy through a strategic alliance between a university and a large health care organization. Academics led groups interested in research. This network had the strongest institutional support and previous research capacity, although it served the smallest population ( 1 million). The center of power was its partner institutions. Ties developed particularly around the interest groups that also served as nodes.

This network had the highest percentage of local participation and 6 times more external grant income than the others, on average. It supported 80 individual researchers, of whom 50 had an academic post, to undertake 36 projects. By December 2001, it had 20 peer-reviewed publications. It was less good at developing new researchers, who mainly collaborated in the research of experts rather than led research themselves.

This network shows the power of strategic institutional alliances and existing academic expertise to attract funding and gain institutional stability. This pattern complements the SDO conclusion that hierarchical networks "are most successful in coordinating and controlling apredefined task that involves complex division of labour."

\section{Network C}

Network C, which has an individualistic/bottom-up structure, covered the largest population -3 million people. Part of its geographic area had a strong tradition of 
primary care leadership on quality initiatives. A parallel guidelines network encouraged recruitment to expert-led research projects. Authority was centered in the steering group, which included representatives of 4 universities and the 7 research practices. Ties were strongest between the research practices and weaker in other places. Nodes developed in response to specific initiatives.

As a result of the strong practice focus of this network, it had the highest number of projects that involved only general practices (37). It supported 140 individual researchers, of whom 31 had an academic post, to undertake 57 projects. By December 2001, it had 18 peer-reviewed publications. Although the network was initially rooted in the founding practices, with time, it sought to balance this by promoting multidisciplinary participation by pharmacists, nurses, and practice managers.

The network's approach shows the potential of local practices to be centers of research activity where multidisciplinary teams reflect on practical primary care concerns. This pattern complements the SDO conclusion that individualistic networks "are most successful for exploring innovations and flexible working practices."7

\section{Network D}

Network D, which has a whole-system leadership, operated in an area where several hospitals and universities were very active in research, but with little primary care collaboration. Few local primary care practitioners had local academic roles, and initially, there was no primary care hot spot for research development. (This network was at first unable to find a primary care organization to host its management and finances.) At the annual conference, a large-group exercise $^{11}$ produced consensus about research themes for the coming year. An annual cycle of activity included stages (nodes) where academics and practitioners were helped to translate themes into practical projects. ${ }^{1,12}$ Those who engaged in each stage provided suggestions about the network as a whole to the steering group, which met monthly to coordinate the various strands of intelligence. This arrangement provided a set of interconnected nodes, each of which allowed participants to contribute to the design of research projects and also to overall network strategy. This had a decentralizing effect on network policy. Ties were evident around the nodes and the project teams.

The emphasis on brokering multidisciplinary research partnerships gave this network the most partnerships between general practices and other organizations (29 [94\%]). It supported 137 individual researchers, of whom 35 had an academic post (in 15 different academic departments), to undertake 31 projects. By December 2001, it had 15 peer-reviewed pub- lications. This productivity was comparable to that of Network B or C, even though this network's previous primary care research capacity was much less. Its weakness was poor institutional support, making it vulnerable to the pressures of powerful stakeholders.

This network shows the power of whole-system methods to integrate stakeholders' efforts. There is no comparable SDO category for this network's structure, a structure that may offer a unique insight into methods to coordinate the agendas of different stakeholders.

\section{DISCUSSION}

This comparative case study illustrates how circumstances influence a network's organization. Different circumstances also lead to imperfect comparisons between them (Supplemental Appendix, Limitations of Our Study). Nevertheless, the data suggest that different types of organization are associated with different outcome profiles. In time, any network may wish to adopt the strengths of each of these networks; that is, it may wish to secure in ways that are appropriate to its own context: learning spaces, top-down institutional and academic leadership, bottom-up ownership by local practitioners, and mechanisms by which different members can contribute to the evolution of the network as a whole.

Together, these approaches may be able to facilitate ongoing creative interactions that lie at the heart of generating new intellectual capital. ${ }^{8}$ Creative interactions between different disciplines may also help to reduce the social and cognitive boundaries known to retard the spread of innovations, ${ }^{13}$ and help to develop trusted relationships across organizational boundaries, known to enhance personal performance in knowledgeintensive work. ${ }^{14}$

\section{The Value of Collaboration}

The added value of integrating different efforts for research is revealed in the far greater productivity of Networks B, C, and D relative to Network A, and the ability of Network D to overcome its limited research capacity through whole-system working.

Reconciling priorities of different stakeholders takes time and requires respect for different needs. Funders are most interested in traditional research outputs (research income and high-impact, peer-reviewed publications), but for those who take up the opportunities offered by involvement, other personal factors such as professional development may be at least as important. ${ }^{15}$

In the short term, universities may be ambivalent about committing effort to collaboration with service partners, because this commitment may not immediately lead to the grant income and peer-reviewed 
publications that are the mainstay of the Research Assessment Exercise, which determines their funding in the United Kingdom. ${ }^{16}$ They may recognize that academic-practitioner partnerships will facilitate later access to health service settings ${ }^{17}$ but may elect to focus resources on existing research teams. Conversely, PCOs may be ambivalent about engaging in research if they see it as distracting from service priorities, and practitioners may fear that research participation will itself become a barrier to practice improvement. ${ }^{18}$

Even in the short term, however, both universities and primary care practitioners stand to gain considerably from an integrated approach. As Chen and Majeed argue ${ }^{19}$ networks may reduce the work involved in developing partnerships because they reach into many organizations and institutions. We hypothesize further that an integrated approach that focuses on developing relationships and capacity, as well as producing research, will lead to the most sustainable network capacity.

\section{Managing Networks of Networks}

To cope with the broader task of integrating clinical and research networks, Network D offers a model of connected learning spaces (nodes). These spaces provide pathways to engage stakeholders from throughout the whole system. This approach requires a diagram to show how the nodes are intended to relate to each other and timetables for making decisions. For example, forums for commissioning, data management, and teaching could serve as 3 connected nodes with the shared purpose of improving quality; each node could be connected with networks for research, clinical excellence, and audit.

We conclude that generic primary care networks could help integrate academic and service initiatives for research purposes and, equally importantly, development purposes. Leaders must, however, ensure that managing the complex interactions involved does not impede good primary care research. Hickner ${ }^{20}$ asserts that the power of practice-based research networks is the ability to help practitioners examine carefully what matters in practice and test these ideas in a broader field with friends who are skilled at collaboration. We must not lose this original inspiration.

To read or post commentaries in response to this article, see it online at http://www.annfammed.org/cgi/content/full/4/3/235.

Key words: Primary care; practice-based research; network; leadership; organizations

Submitted May 11, 2005; submitted, revised, September 29, 2005; accepted October 24, 2005.

Findings were presented in an MD thesis that was granted by Liverpool University, Liverpool, England, in 2003. Findings were also presented at the North American Primary Care Research Group in Banff, British Columbia, in 2003.
Funding support: This work was funded by NHS Research and Development funding to the West London Research Network (WeLReN).

Acknowledgments: We thank the administration staff of all 4 networks, especially WeLReN, that funded this work and provided encouragement and support. We give thanks also to all the researchers who so willingly provided data that enabled the cross-network comparisons.

\section{References}

1. Thomas P, Griffiths F, Kai J, O'Dwyer A. Networks for research in primary health care. BMJ. 2001;322:588-590.

2. Martin JC, Avant RF, Bowman MA, et al. The Future of Family Medicine: a collaborative project of the family medicine community. Ann Fam Med. 2004;2(Suppl 1):S3-S32.

3. Department of Health. The New NHS, Modern, Dependable. London, England: HMSO; 1997.

4. Department of Health. Best Research for Best Health. A new national health research strategy. London, England: DH. 2006.

5. Department of Health. Making Practice Based Commissioning a Reality: Technical Guidance. February 2005. Available at: http://www.dh.gov. uk/assetRoot/04/10/50/33/04105033.pdf. Accessed 22 March 2006.

6. Weber M. The Methodology of the Social Sciences. New York, NY: Free Press; 1949.

7. Goodwin N, Peck E, Freeman T, Posaner R. Networks Briefing-Key Lessons for Networks. London, England: NHS Service Delivery and Organisation Programme; 2004.

8. Harvey J, Fenton E, Sturt J. Evaluation of Primary Care RED Networks in North Thames Region. Warwick, England: Centre for Creativity, Strategy and Change, Warwick Business School, University of Warwick; 2000

9. Brass DJ, Galaskiewicz J, Greve HR. Taking stock of networks and organizations: a multilevel perspective. Acad Manag J. 2004;47:795-817.

10. Mayo M, Meindl JR, Pastor J-C. Shared leadership in work teams: a social network approach. In: Pearce CL, Conger JA, eds. Shared Leadership: Reframing the Hows and Whys of Leadership. Thousand Oaks, Calif: Sage Publications; 2003.

11. Benedict BB, Alban B. Large Group Interventions-Engaging the Whole System for Rapid Change. San Francisco, Calif: Jossey-Bass; 1997.

12. Thomas $P$, While $A$. Increasing research capacity and changing the culture of primary care towards reflective inquiring practice: the experience of the West London Research Network (WeLReN). J Interprof Care. 2001;15:133-139.

13. Ferlie E, Fitzgerald L, Wood M, Hawkins C. The nonspread of innovations: the mediating role of professionals. Acad Manag J. 2005;48:117-134.

14. Cross R, Cummings JN. Tie and network correlates of individual performance in knowledge-intensive work. Acad Manag J. 2004;47:928-937.

15. Bateman $H$, Kinmonth $A-L$. Learners and funders: incorporating principles from educational guidance into the evaluation of advisory support for practitioners interested in research. Educ Primary Care. 2002; 13:215-222.

16. Banatvala J, Bell P, Symonds $M$. The Research Assessment Exercise is bad for UK medicine. Lancet. 2005;365:458-460.

17. Hammersley V, Hippisley-Cox J, Wilson A, Pringle M. A comparison of research general practices and their patients with other practicesa cross-sectional survey in Trent. Br J Gen Pract. 2002;52:463-468.

18. Bodenheimer T, Young DM, MacGregor K, Holtrop JS. Practicebased research in primary care: facilitator of, or barrier to, practice improvement? Ann Fam Med. 2005;3(Suppl 2):S28-S32.

19. Chen F, Majeed A. Primary care trusts and primary care research. BMJ. 2005;330:56-57.

20. Hickner J. Practice-based network research. In: Bass MJ, Dunn EV, Norton PG, Stewart M, Tudiver F, eds. Conducting Research in the Practice Setting. Newbury Park, Calif: Sage Publications; 2000. 